\title{
Gömülü Sistem Tabanlı EKG Holter Cihazının Tasarlanması
}

\author{
${ }^{* 1}$ Ahmet Yesevi TÜRKER ${ }^{* 1}$ Muhammed GÜLER ${ }^{2}$ Mustafa Zahid YILDIZ, \\ ${ }^{* 1}$ Fen Bilimleri Enstitüsü, Biyomedikal Mühendisliği Anabilim Dalı Biyomedikal Mühendisliği \\ Sakarya Üniversitesi, Türkiye \\ ${ }^{2}$ Teknoloji Fakültesi, Elektrik Elektronik Mühendisliği Sakarya Üniversitesi
}

\begin{abstract}
Özet
Ülkemizde ve dünyada nüfusun giderek yaşlanması ve kalp rahatsızlıklarının artması, bu hayati organımızın faaliyetlerini sürekli kontrol altında tutma, tedavi sürecinde ve öncesinde tüm etkileri gözlemleme gibi ihtiyaçları doğurmaktadır. Çalışmanın temel amacı, açık kaynak kodlu, geliştirilmeye açık gömülü sistem tabanlı taşınabilir bir EKG Holter cihazını gerçekleştirmektir. Yapmış olduğumuz çalışma üç aşamadan oluşmaktadır: İlk aşamada, bireyin Elektrokardiyografi (EKG) sinyalleri tasarladığımız biyoenstrümantasyon yükseltici devresi ile toplanarak yaklaşık 200 kat kuvvetlendirilmiş ve sonraki sinyal işleme aşamasına uygun hale getirilmiştir. Şebeke gürültüsünü bastırmak üzere EKG sinyallerine $50 \mathrm{~Hz}$ 'lik çentik filtre ve bant genişliği 0,01 - $130 \mathrm{~Hz}$ arasında olan bant geçiren filtre uygulanmıştır. İkinci aşamada ise analog EKG işareti Analog Dijital Çeviriciler kullanılarak sayısallaştırılmıştır. Haberleşme protokolleri yazılarak gömülü sistem kartlarıyla bağlantısı kurulmuştur. Üç farklı gömülü sistem kartı ile sinyal işleme algoritmaları uygulanacak hale getirilmiştir. Tasarladığımız arayüz ilk olarak çok sayıda kütüphane desteği olması sebebiyle Python dilinde geliştirilmiş. Ancak bu dilin yazdığımız sinyal işleme algoritmasını çalıștırma hızı yeterli olmadığından $\mathrm{C}++$ dilinde programlama yapılmaya geçilmiștir. Üçüncü aşamada, 10 farklı katılımcıdan $100 \mathrm{sn}$. süresince 3'er adet a- dinlenme halinde ve b- merdiven inme çıkma hareketinin ardından EKG verileri kaydedilmiştir. Daha sonra, Raspberry Pi, Beaglebone ve Odroid gömülü sistem kartları arasındaki hız farkları ve performansları analiz edilerek karşılaştırılması yapılmış ve sonuçlar incelenmiștir. Beaglebone kullanılarak örnekleme hızı 35 Hz’i geçemediğinden EKG için kullanımının uygun

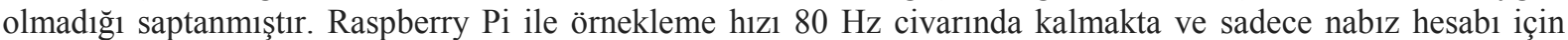
kullanılabileceği saptanmıştır. Odroid' de ise örnekleme hızı $250 \mathrm{~Hz}$ civarına çıkabildiğinden ECG analizi için en uygun mikrobilgisayar olarak belirlenmiştir.
\end{abstract}

Anahtar Kelimeler: EKG Holter, Gömülü Sistem, R-R aralık.

\section{Design of a Microcomputer Based Realtime ECG Holter Device}

\author{
${ }^{*}$ Ahmet Yesevi TÜRKER ${ }^{* 1}$ Muhammed GÜLER ${ }^{2}$ Mustafa Zahid YILDIZ, \\ ${ }^{* 1}$ Fen Bilimleri Enstitüsü, Biyomedikal Mühendisliği Anabilim Dalı Biyomedikal Mühendisliği \\ Sakarya Üniversitesi, Türkiye \\ ${ }^{2}$ Teknoloji Fakültesi, Elektrik Elektronik Mühendisliği Sakarya Üniversitesi
}

\begin{abstract}
The growing aging population rate in our country and all over the world and increase in heart diseases lead to some requirements; in fact, it's indispensable to keep activities of this vital organ under control and observe all the effects of during and pre-treatment process. The primary goal of this study is to design a specifically developed device that will facilitate human life by any means of the specifications and implementation of portable ECG Holter device with open source software and upgradeable embedded system. The study that we have conducted consists of 3 phases; The 1st phase made it suitable to signal processing stage by compiling EKG signals with the aid of bioinstrumentation amplifier circuit that we developed. Afterwards, bioinstrumentation amplifier and signals raised by 205 times. In order to suppress network noise, 50HZ notch filter was implemented on ECG Signals and a Butterworth filter with the bandwidth of $0.01-130 \mathrm{~Hz}$ was used. In the 2nd phase, analog ECG sign, provided by the participants was digitized by using analog digital converters. It was linked up with embedded system cards via communication protocols. Three different types of embedded system cards and signal processing algorithm were setup and the interface that we designed was developed in Python language owing to a great number of libraries. However, it was replaced by another programming in $\mathrm{C}++$ language since this language did not allow signal processing algorithm function well due to lack of operating speed. In the 3rd phase, ECG data was recorded after 10 different participants moved upstairs and downstairs at intervals of $100 \mathrm{sec}$, followed by breaks of 3 times.
\end{abstract}

Sorumlu Yazar: Ahmet Yesevi Türker, Adres: Fen Bilimleri Enstitüsü, Biyomedikal Anabilim Dalı, Biyomedikal Mühendisliği, Sakarya Üniversitesi, 54187, Sakarya TÜRKİYE. E-mail: yesevi.turker@ogr.sakarya.edu.tr 
Later on, the Raspberry Pi, Beaglebone and Odroid embedded system cards were compared in terms of speed differences and performances, and also consequences were analyzed. Since the sampling rate with Beaglebone didn't exceed $35 \mathrm{~Hz}$, it was determined that this was inappropriate for the use of ECG. The sampling rate with Raspberry Pi remained around $80 \mathrm{~Hz}$ and it was confirmed that this could be used only for checking the pulse. As far as Odroid is concerned, since sampling rate went up to around $250 \mathrm{~Hz}$, It was assigned to be the best microcomputer.

Keywords: ECG Holter, Embedded Operating System, R-R interval

\section{GİRIŞ}

Her geçen yıl, kronik rahatsılıklardan, geç müdahalelerden ve sağlı hizmetlerinin yetersiz kalmasından dolayı binlerce insan yaşamını yitirmektedir. Sağlık tetkiklerinin artışına ve taşınabilir medikal cihazların gelişim ve kullanımının artışına yönelik insanların beklentisi artık oldukça yüksektir. Araştırmalar doğrultusundaki öngörülere göre, 2050 yılında Avrupa nüfusunun \%40 '1nın 65 yaş üzerine çıkması beklenmektedir [1]. Nüfus yaş ortalamasının yükselmesi, çevresel faktörlerden kaynaklanan stres ve sıkıntıların artışı, hayati önem taşıyan kalbimizi tehdit altına almaktadır. Bununla birlikte, her yıl yaklaşık olarak 7,2 milyon insan, ölüm sebeplerine göre ilk siralarda yer alan kronik kalp rahatsızlıklarından dolayı hayatını kaybetmektedir [2].

Hayati önem taşıyan kalpteki ritim bozukluklarının önceden tespit edilebilmesinde, EKG verilerinin değerlendirilmesi erken müdahale için oldukça önemlidir. Pratikte ritim bozuklukları dönemsel olma özelliği taşıdığı için hastane ortamındaki EKG ölçümlerinde saptanması zordur. Bu nedenle uzun süreli EKG kayıtlarına ihtiyaç duyulur. EKG aktivitesinin 24 saat veya daha uzun süreli olarak kaydedilmesi için kullanılan cihazlara "Holter" adı verilmektedir [3, 4].

Tanı amaçlı kullanılan EKG (elektrokardiyogram) işaretleri insan vücudu üzerinde algılanabilen ve kalbin elektriksel aktivitesinin sonucu olarak ortaya çıkan belli tipteki biyolojik işaretlerdir [5, 6]. Normal bir durumda, kalp hücreleri elektriksel olarak kutuplaşmıştır. Kalp hücrelerinin iç kısımları negatif yüklü iken, dış kısımları pozitif yüklüdür. Kalbin en önemli işlevi kutuplaşmayı kaldırma (depolarizasyon) olarak adlandırılır. Kutuplaşmayı kaldırma işlemi sürecinde kalp hücreleri normal negatifliğini kaybedebilir. $\mathrm{Bu}$ işlem hücreden hücreye yayılarak, tüm kalbe aktarılan bir depolarizasyon dalgası oluşturur. Elektrik akımının dolaşımı, bu depolarizasyon dalgası tarafından üretilir. Vücuttaki elektrotların yardımı ile bu akım tespit edilebilir. Depolarizasyon tamamlandığında, kalp hücreleri, aynı zamanda elektrotlar tarafindan da algılanan ve repozalizasyon olarak adlandırılan bir işlem ile normal kutupluklarına geri döner [7].

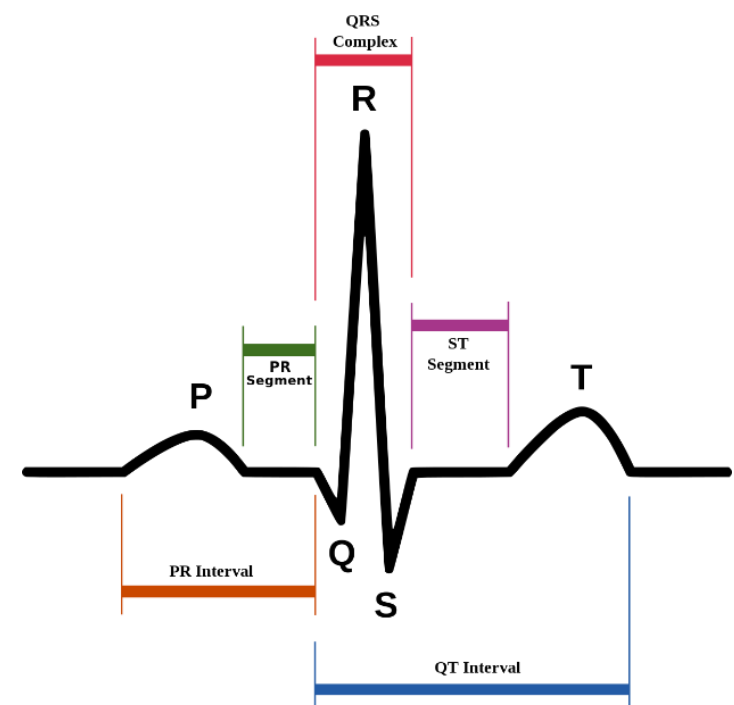

Şekil 1 Bir İnsan EKG İşaretinin Dalga Formu.

Şekil 1'deki [8] EKG'nin bir örneği, beş pozitif ve negatif tepe noktası (peaks and valleys) olarak nitelendirilip, harflerle $\mathrm{P}, \mathrm{Q}, \mathrm{R}, \mathrm{S}$ ve T olarak etiketlendirilerek gösterilmiştir. EKG analizi bu piklerin doğru ve güvenilir olarak tespit edilmesine bağlıdır. EKG analizinde, QRS kompleksini tanımlama çok önemli bir görevdir. QRS kompleksi kesin olarak doğru bir şekilde tanımlandığında ve detaylandırıldığında, kalp hızı hesaplanabilir ve ST segmenti gibi bazı diğer analizler yapılabilir.

Kalp rahatsızlıklarının artması, hem ülkemizde hem dünyada bu hayati organımızın faaliyetlerini sürekli kontrol altında tutma ve tedavi sürecinin etkilerini gözlemleme gibi ihtiyaçları doğurmaktadır. Tüm tedavi süreci ve öncesinde hastanın en hayati organının tüm detaylarıyla tetkiki en öncelikli aşamalardan birisidir. Hastanelerin kısıtlı imkânları ve hastaların sürekli hastaneye gitme zorlukları, mobil ölçüm ve takip sistemlerini gerekli kılmaktadır [9].

Kalp rahatsızlıklarının muhatabı olan hastaların kontrole gitmeleri mevcut durumlarından dolayı zor olduğundan ve hastanelerin yatakhane sayılarının bazı durumlarda yeterli olmamasından dolayı uzun vadeli ve belli periyotlarda EKG ölçümü yapılması zordur. Bu yüzden taşınabilir, kullanımı kolay mobil EKG Holter cihazlarının tasarlanması ve kullanıma sunulması gerekmektedir. Tasarlamış olduğumuz cihaz uzun süreli $\mathrm{EKG}$ verisi kayıt 
edebilmektedir [3]. Bu verileri günlük, aylık ve yıllık şekilde kaydedip, tedavi süresince birbirleri ile karşılaştırıp, hastalığın iyileşme derecesini inceleme imkanı sunmaktadır.

$\mathrm{Bu}$ çalışma kapsamında tasarlanmış olan EKG Holter cihazının kullanım alanlarının doğal bir geliştirme ve yenileme döngüsüne girmesi üretilebilirliği arttıracağ ${ }_{1}$ için tercih edilmiştir. $\mathrm{Bu}$ sebeple Raspberry Pi ve Beaglebone gibi popüler gömülü sistem kartları kullanılmıştır [10]. Tasarlanan analog devreler ve analiz algoritmalarının testleri için sağlıklı kişilerden veriler toplanarak hangi gömülü sistem kartlarının güvenilir bir holter cihazı olarak tasarlanabileceği gösterilmiştir.

\section{Yöntem}

Biyomedikal alanında yapılan çalışmalar biyopotansiyel sinyallerin ham şekilde elde edilip, tasarlanan filtreler ile gürültülerin bastırılması ve biyopotansiyel sinyaller üzerinde işlem yapılması, sonuç üretilmesi ve yorumlanması ile ortaya çıkar. EKG sinyalleri elektrik kökenli işaret olup biyopotansiyel sinyal olarak adlandırılır. Biyopotansiyel sinyallerin genlikleri $\mu \mathrm{V}-\mathrm{mV}$ 'lar civarında seyretmektedir. $\mathrm{Bu}$ sinyaller $\mathrm{Ag}-\mathrm{AgCl}$ yüzey elektrotları EKG ölçümü alabilmek için uygun yerlere konumlandırılarak sinyaller toplanır. Elde edilen sinyaller biyoenstrümantasyon yükselteci ile yükseltilir. Analog devrede kullanılacak biyoenstrümantasyon yükselteci seçimi, devre tasarımının en önemli basamağıdır. Biyoenstrümantasyon yükselteci seçimi yapılırken ortak modu bastırma oranı (CMRR) ve kazanç katsayısına dikkat edilmelidir. Yükseltilen EKG sinyalinin anlaşılabilir ve üzerinde işlem yapılabilir hale gelmesi için $0,1 \mathrm{~Hz}$ ile $130 \mathrm{~Hz}$ arasında bant geçiren filtre uygulanmıştır. $50 \mathrm{~Hz}$ şebeke gürültüsünün devre üzerindeki olumsuz etkisini yok etmek için 'çentik filtresi' tasarımı gerçekleştirilmiştir. Gürültülerden arındırılan EKG sinyali analog dijital çeviriciler kullanılarak sayısallaştırılarak haberleşme protokolleri uygulanmış ve gömülü sistem kartıyla entegre edilmiştir. İşlem basamakları Şekil 2'de görüldüğü gibi adım adım uygulanmıştır.

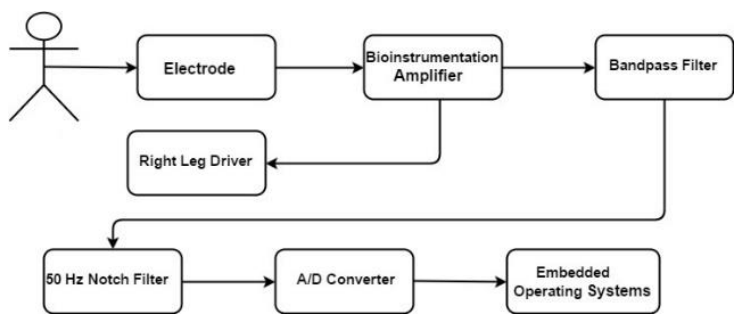

Şekil 2 EKG Holter Sisteminin Blok Diyagramı.

\subsection{Elektronik Devre Tasarımı}

\subsubsection{EKG Devre Tasarımı}

Tasarlamış olduğumuz analog devrede elde edilen sinyaller biyoenstrümantasyon yükseltecinden geçirildikten sonra sinyal ile birlikte gürültülerde yükseldiği için birinci dereceden pasif bant geçiren ve $50 \mathrm{~Hz}$ çentik filtre uygulanmıştır. Kullanmış olduğumuz MCP3208 analog dijital çevirici (ADC) 0-3,3 volt aralığında çalışması için ADC'nin girişine seviye ayarlayıcı devre tasarlanmıştır. Sayısallaştırılan EKG verisi Serial Peripheral Interface (SPI) protokolü kullanılarak gömülü sistem kartı ile haberleştirilmiştir. Analog devre dizaynı şekil 3 'te görüldüğü gibidir.

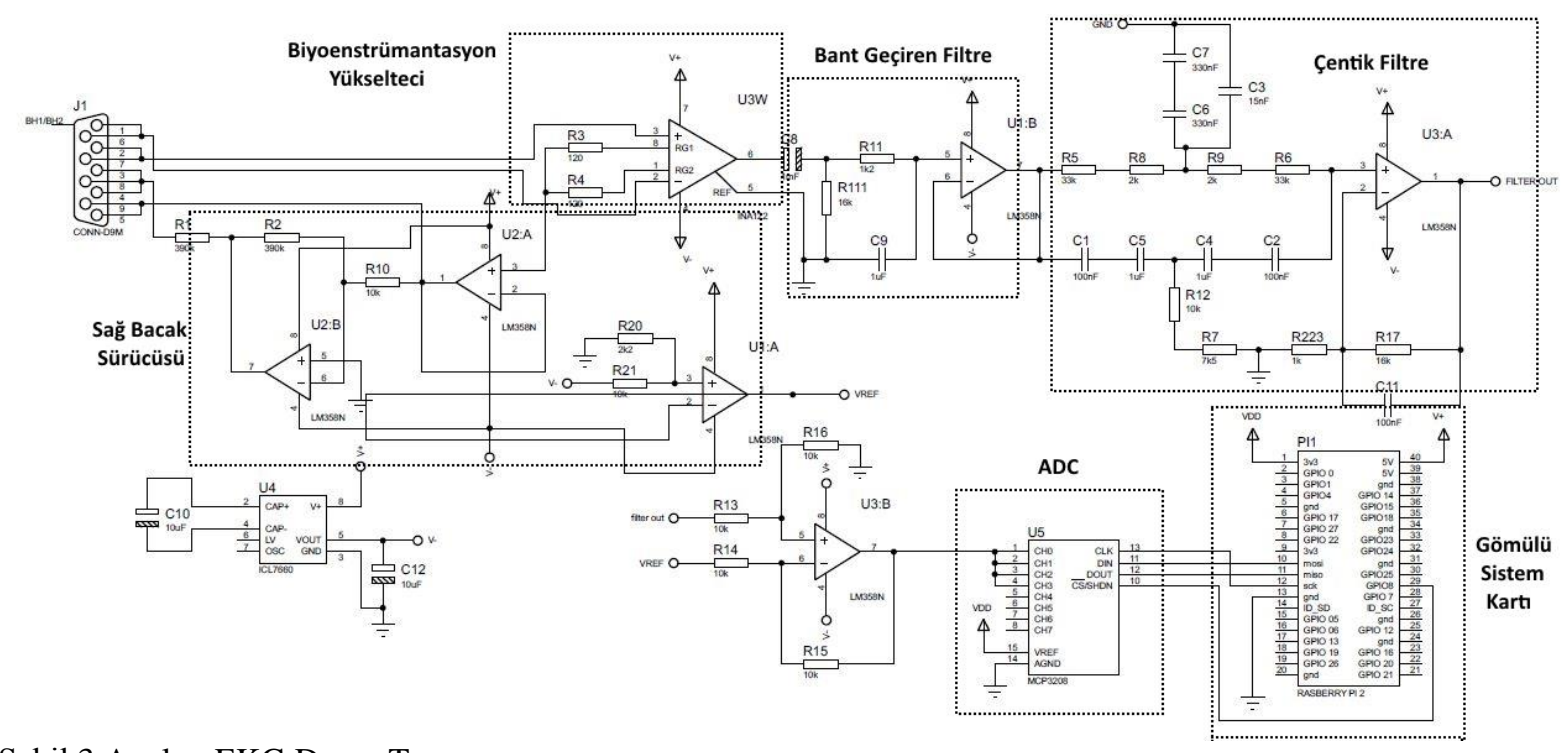

Şekil 3 Analog EKG Devre Tasarımı. 


\subsubsection{Biyoenstrümantasyon Yükselteci}

Biyoenstrümantasyon yükselteci seçimi yapılırken ilk olarak hesaplanması gereken hususlar; optimum kazanç ve ortak modu bastırma oranıdır (CMRR). Kullanilacak olan biyoenstrümantasyon yükseltecinin malzeme gürültüsü düşük seviyelerde ve giriş empedansı M $\Omega$ 'lar civarında olmalıdır. Aynı zamanda elektriksel yalıtımlı biyoenstrümantasyon yükselteci seçilerek statik elektrik, defibrilatör gibi çevresel etmenlerden etkilenmeden sağlıklı ölçümler alınır.

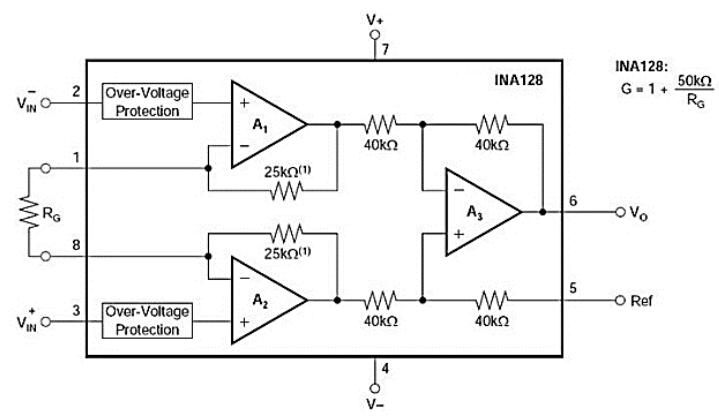

Şekil 4 Biyoenstrümantasyon Yükselteci Ve Kazanç Ayarlanmas1 [12].

Devre tasarımında biyoenstrumantasyon yükselteci olarak Texas Instruments INA 128 entegresi kullanılmıştır. Şekil 4'teki INA 128 biyoenstrumantasyon yükseltecinin kazanc1 ayarlanırken $\mathrm{G}=5+\frac{50 k \Omega}{R G}$ (1) yükseltme kat sayısı denklem 1 ,

$$
\begin{gathered}
G=5+\frac{50 k}{200}=255 \\
\text { olarak hesaplanmıştır [12]. }
\end{gathered}
$$

\subsubsection{Sağ Bacak Sürücüsü (RLD)}

Modern EKG sistemlerinde hasta asla topraklanmaz. Bunun yerine, sağ bacak yükseltecinin çıkışına bağlanır. İki eşik değer arasındaki ortak mod gerilimi alınır, ters dönüştürülür, yükseltilir ve sağ bacağa geri beslenir. $\mathrm{Bu}$ negatif geri bildirim ortak mod voltajını düşürür. Sızıntı akımı, zemin yerine yardımc1 opamp vasitasıyla vücuda akar. Bu bağlantı, hastanın etkileşimi bağlamasını ve azaltmasını engeller. Bu devre aynı zamanda bir elektrik izolasyonu görevi görür. Hasta ve şase arasında çok yüksek bir gerilim varsa, yardımcı amplifikatör doyuma gider ve hastayı korur $[6,11]$.

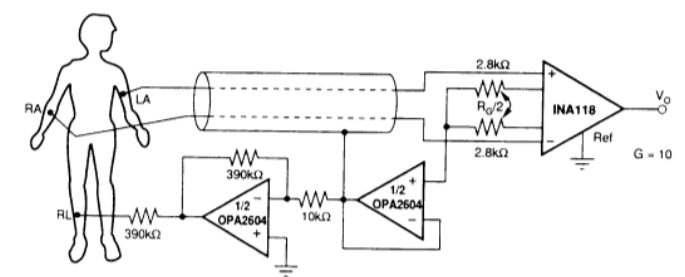

Şekil 5 Sağ Bacak Sürücüsü Devresi [6].

Biyopotansiyel işaretler fark sinyalleri şeklinde elde edilir. Bir enstrümantasyon yükselteci üç işlemsel yükselteç içeren yapıdan geliştirilmiştir. Her bir girișteki sinyal ve giriş sinyallerinin ortalamasına eşit olan ortak mod gerilimi yükseltilir. Şekil 5'teki analog devre model olarak alınmıştır. Kullanılan INA128 entegresi 255 kat yükseltme işlemi gerçekleştirmiştir.

\subsubsection{Bant Geçiren Filtre Tasarımı}

Bant geçiren filtreler, istenen bant aralığında frekansları geçiren ve diğer frekansları bloke eden türden bir filtredir. Şekil 6'daki gibi bir bant geçiren filtre tasarlanırken ilk olarak alçak geçiren filtre tasarımı yapılır ve alçak kesim frekansı ayarlanır, ardından yüksek geçiren filtre tasarımı yapılarak yüksek kesim frekansı hesaplanır $[13,15]$.

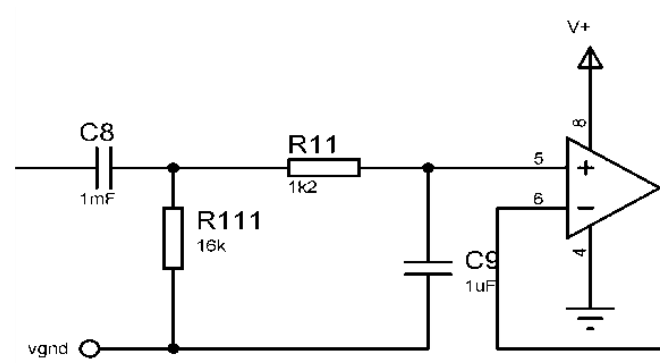

Şekil 6 Bant Geçiren Filtresi Devresi.

Tasarlamış olduğumuz analog devre, gömülü sistem kartı ile beslendiği için 5 volt besleme gerilimi ile çalışan LM358 entegresi tercih edilmiştir.

LM358 opamp'ının pozitif girişi referans gerilimine bağlanarak opamp eviren yükselteç olarak kullanılmıştır. Denklem 2 ve denklem 3 kullanılarak filtrenin alçak kesim ve yüksek kesim frekansı hesaplanır.

$$
\begin{aligned}
f_{h}= & \frac{1}{2 x \pi x R_{111} x c_{8}} \\
f_{h}= & \frac{1}{2 \times \pi \times 1.2 \times 10^{2} \times 1 \times 10^{-6}}=132 \mathrm{~Hz} \\
& f_{l}=\frac{1}{2 \times \pi \times R_{11} \times C_{9}} \\
f_{l}= & \frac{1}{2 \times \pi \times 16 \times 10^{3} \times 1 \times 10^{-3}}=0.011 \mathrm{~Hz}
\end{aligned}
$$

\subsection{5. Çentik Filtre Tasarımı}

$50 \mathrm{~Hz}$ 'lik şebeke frekanslı gürültülerin sinyale olan bozucu etkisini sönümlemek için çentik filtre devresi kullanılır. Denklem 4' teki formülden yararlanılarak tasarlamış olduğumuz çentik filtresi bant genişliğini $50 \mathrm{~Hz}$ 'in çevresinde $\mp 1 \mathrm{~Hz}$ salınım yaparak BW =2 olacak şekilde 49-51 Hz frekans aralığında tasarlanmıştır.

Çentik filtreleri yapmak için birçok metot vardır. Bunlardan biri, bir yüksek geçiren ile alçak geçiren filtreyi paralel bağlamak diğeri de seri rezonans ile 
yapılabilir. Şekil 7 (a)'da çentik pasif filtre devresi, şekil 7 (b)'de ise simülasyon çıktısı görülmektedir $[14,15]$.

(a)

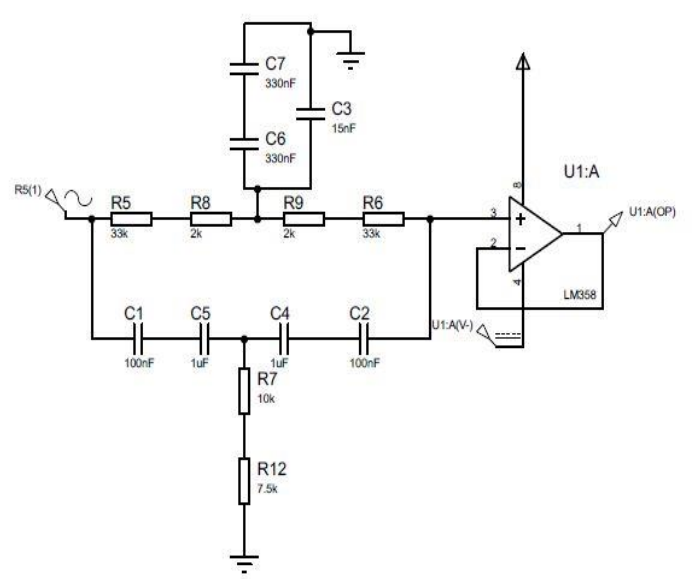

(b)

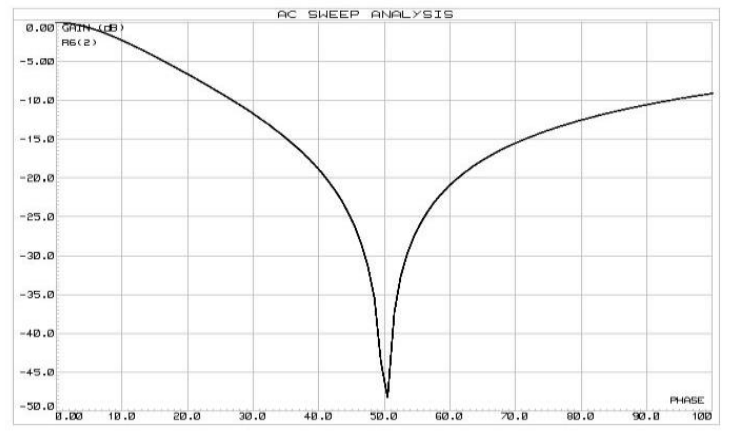

Şekil 7 (a) Çentik Filtre Devresi (b) Çentik Filtre Simülasyon Çıktısı.

$\mathrm{R}=35 \mathrm{k}$

$\mathrm{C}=90 \mathrm{pF}$

$\mathrm{f}_{0}=\frac{1}{2 \times \pi \times \mathrm{R} \times \mathrm{C}}$

$$
f_{0}=\frac{1}{2 \times \pi \times 35 \times 10^{3} \times 90 \times 10^{-9}}=50 \mathrm{~Hz}
$$

\subsubsection{Dijital Filtre Tasarımı}

Biyoenstrümantasyon yükselteci ile yükseltilen EKG sinyalleri, çevredeki gürültüler ile beraber yükseltildiğinde dijital filtrede kullanılan filtre katsayıları çok olacağı için gömülü sistem kartının çalıșma hızını etkiler, bu yüzden ilk olarak analog filtreler uygulanır. Uygulanan analog filtrede kullanılan elamanların da iç gürültüleri olduğundan bu çalışmada analog ve dijital filtre beraber bulunmaktadır $[16,17]$.

Dijital filtre tasarımı MATLAB ile gerçekleştirilmiştir. Filtre tipi olarak FIR filtre tercih edilip, ardından en az katsayı ile istenilen filtre cevabını sağlayan Least Square Method kullanılmıştır. Frekans özellikleri menüsünden örnekleme frekansı ve filtrelenecek frekans aralığ1 ayarlanmıştır. Şekil 8' de görüldüğü üzere multi bant kullanılarak $0-100 \mathrm{~Hz}$ arasında bant geçiren ve 50
$\mathrm{Hz}$ çentik filtre uygulanmıştır. İstenilen karakteristiğe uygunluk ve işlemcinin performansı dikkate alınarak 83 katsayı kullanılması uygun görülmüştür.

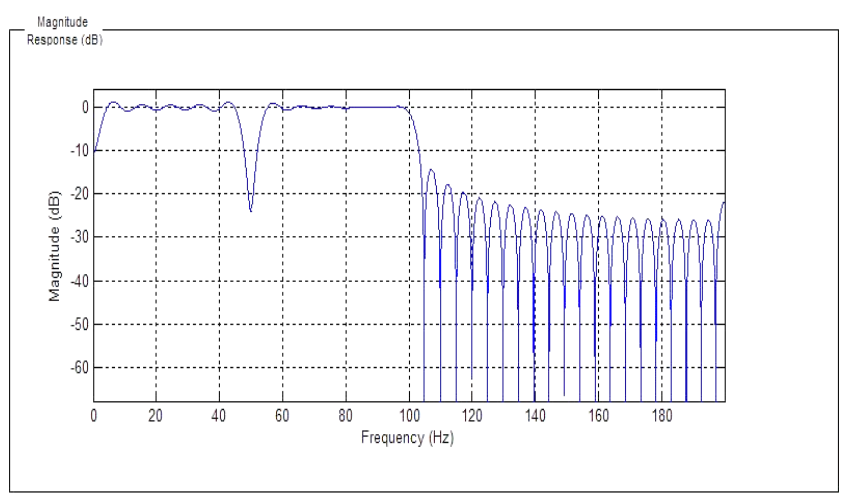

Şekil 8 Matlab Platformunda Dijital Filtre Tasarımı.

Tasarlamış olduğumuz dijital filtreyi test etmek için önceden kaydetmiş olduğumuz gürültülü EKG sinyalini Proteus ortamında hazırladığımız şekil 9 'daki devre tasarımı kullanılmıştır. Programa dâhil olan dijital osilaskop ile gürültülü giriş sinyali ile filtrelenmiş EKG sinyali arasında şekil 10 'da olduğu gibi gösterilip filtrenin çalışması test edilmiştir.

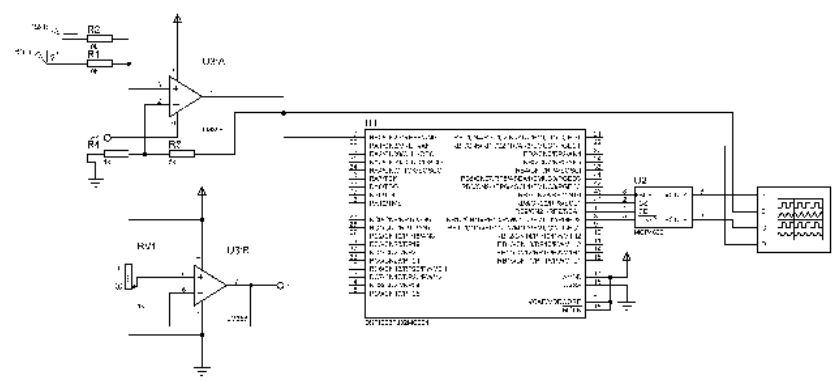

Şekil 9 Dijital Filtrelerin Simülasyon Devresi.

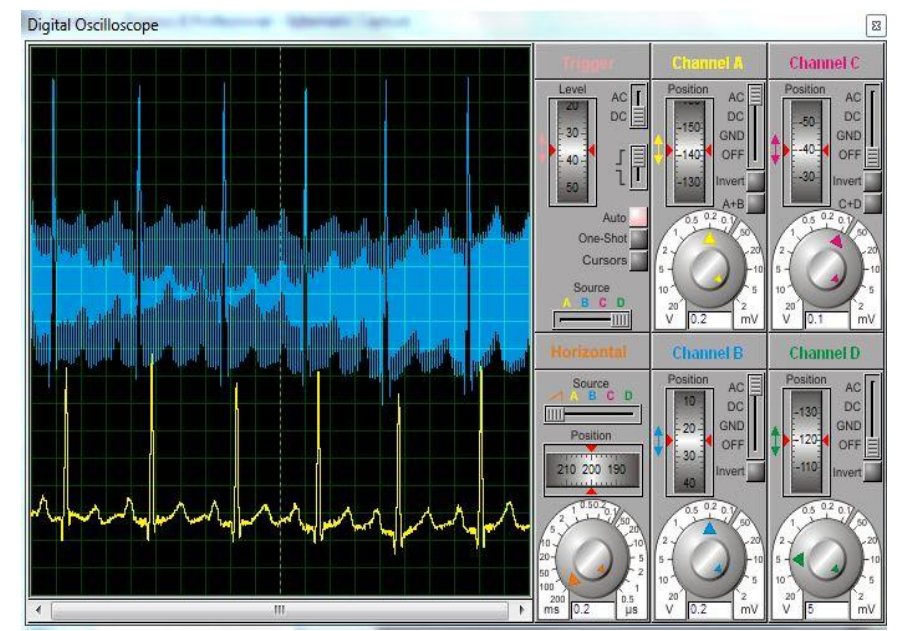

Şekil 10 Filtrelenmiş EKG İşaretinin Simülasyon Çıktısı (Mavi işaret gürültülü sinyali, Sarı işaret ise filtrelenmiş sinyali göstermektedir). 


\subsection{Matlab Analizleri}

\subsubsection{Teager Enerji Operatörü (TEO)}

Teager enerji operatörü sinyale uygulandığı zaman P, Q, S, T tepeleri zayiflarken, R tepesi kuvvetlendirilir. Algoritma oluşturulmasında denklem 5'teki eşitlik kullanılmıştır [24].

$$
\psi_{T S}(n)=\psi_{s}^{2}(n)-\psi_{s}(n-1) \psi_{s}(n+1)(5)
$$

$(\psi s(n): \quad n$ 'inci değer, $\psi \operatorname{Ts}(n): \psi s(n)$ 'in TEO uygulanmış biçimi, Ts: Teager operatörünün çıkışı)

\subsubsection{Sinyal Enerjisi Yöntemi}

Denklem 6'te gösterildiği gibi alınan sinyallerin karelerinin toplanması ile elde edilir [24].

$E=\sum_{k=1}^{M} x(k)^{2}$

(E: Enerji, k: Zaman indisi, M: Süre)

\subsubsection{RR-Aralıklarının Hesaplanması}

RR-aralıkları ortalama değeri, yüzde değerine göre sınıflandırılmaktadır. Eğer yüzde değeri $85^{\prime}$ ten küçükse kısa, yüzde değeri 115 'ten büyükse uzun olarak adlandırılmaktadır. Diğer bütün durumlar düzenli ritim sınıfına girmektedir [18]. Kullanılan algoritma denklem 7'ye göre oluşturulmuştur [18].

$\operatorname{rrmean}(i)=0.75 * \operatorname{rrmean}(i-1)+0.25$

$$
* \operatorname{rr}(i)
$$

\section{Sonuçlar ve Tartışma}

\subsection{Analog Devre Dizaynı}

Tasarlamış olduğumuz Analog EKG devresi, gömülü sistem kartı ve ekran sürücü devresi ile beraber 3 katlı kompakt bir yapıya sahiptir. Analog devre, çalışması için gerekli olan besleme ve toprağı (GND) gömülü sistem kartından sağlamaktadır. Aynı zamanda Gömülü sistem kartı da ekrana ait USB güç çıkışından beslenmektedir. Ana güç kaynağ1 ise 7" lik ekrana güç vermektedir. Sonuç olarak birbirleriyle bütünlük sağlamış 3 katlı devreye sahip bir EKG Holter cihazı Şekil 11'de görüldüğü gibi elde edilmiştir.

Şekil 12 (a) 'da görüldüğü üzere EKG Holter sistemi gerçek zamanlı çalışıp analiz algoritmalarını gerçeklemektedir. Sistemin çıktıları şekil 12 (b)' de ki arayüzde monitörize edilmiştir.

\subsection{Matlab Analizleri}

Kalp sinyallerinin genlikleri kişilere göre değişkenlik gösterir. Dakikada tekrarlanan kalp döngüsü kişiye ait olan nabzı verir. Kalp döngüsünü saptamak için R tepesi kullanılır. Matlab platformunda yapmış olduğumuz algoritmaların temeli $\mathrm{R}$ tepesini güçlendirip diğer tepelerin bastırılması temeline dayanmaktadır.

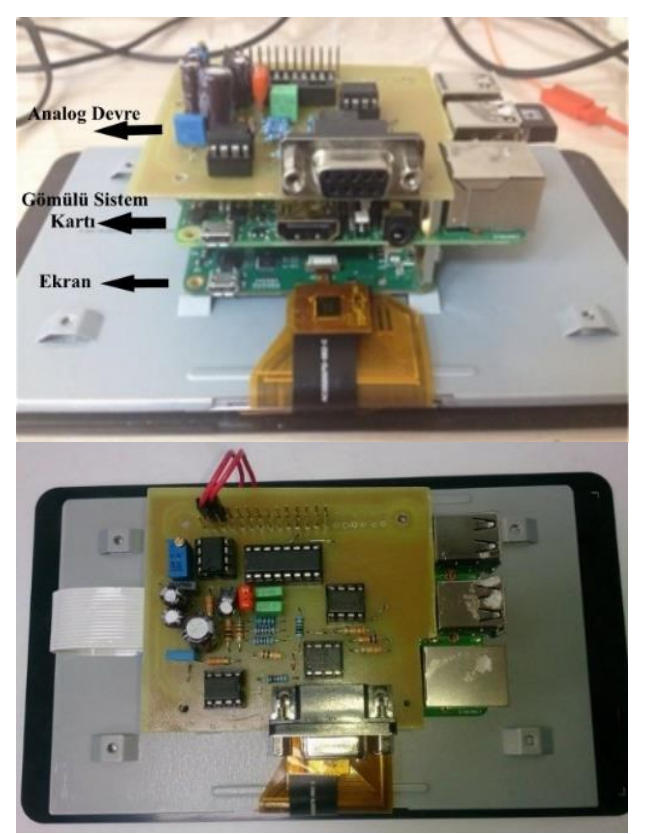

Şekil 11 Kompakt EKG Holter Devresinin Gerçeklenmesi.

(a)

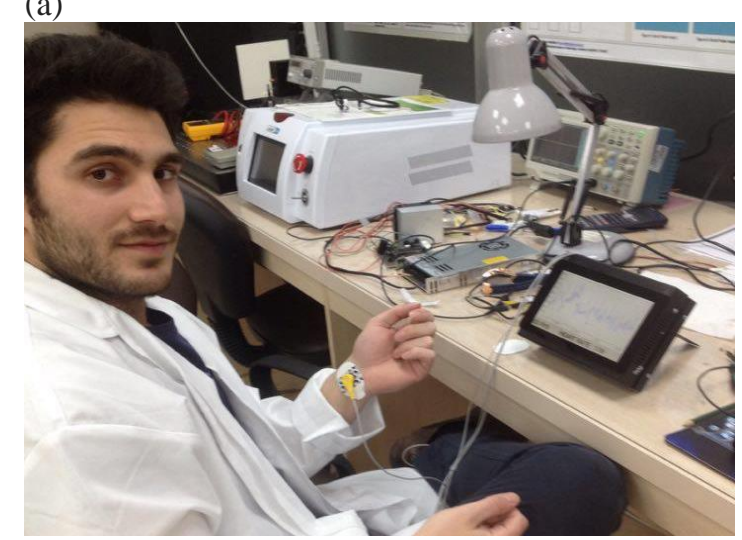

(b)

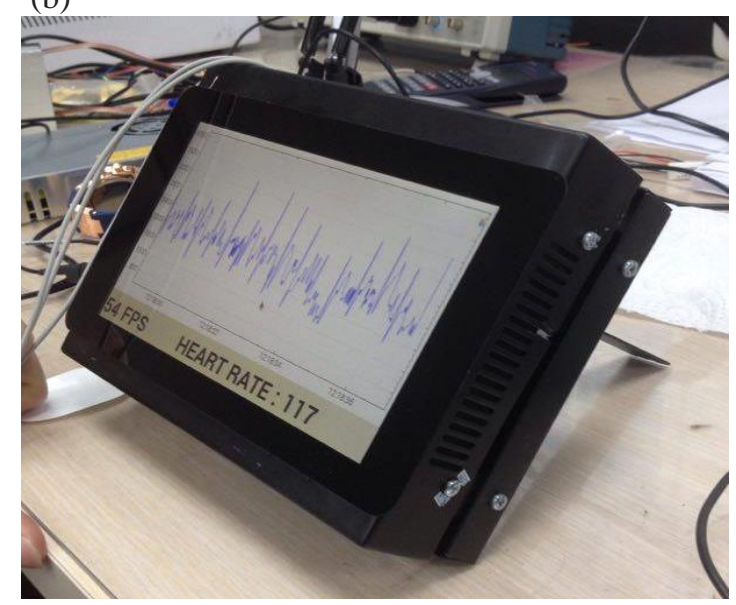

Şekil 12 EKG Holter cihazının gerçek zamanlı çalışması, a)Laboratuvar ortamında cihazın uyarlanması b) Cihazın ekran görüntüsü. 
Tasarladığımız EKG Holter devresi ile kaydettiğimiz EKG verilerini önce Matlab ortamında filtreleme, $\mathrm{R}$ tepe noktalarını belirgin hale getirmek için aşağıda açılanan algoritmaların uygulanması işlemleri gerçekleştirilmiştir. Bu adımlar, gömülü sistem kart üzerinde uygulanarak sonuçlar karşılaştırılmıştır.

\subsubsection{Dijital Çentik ve Bant Geçiren Filtre Tasarımı}

Şekil 13 (a) 'daki grafik, deneklerden analog devre ile kaydedilen, filtrelenmemiş gürültülü $\mathrm{EKG}$ verisidir. Şekil 13(b)'deki grafik, Matlab ortamında yazılan $50 \mathrm{~Hz}$ çentik filtre ve $0,01 \mathrm{~Hz}$ ile $100 \mathrm{~Hz}$ arası bant geçiren filtre algoritmalarından geçirilerek, şebeke ve ortam gürültüsünden arındırılan EKG verisidir. $\mathrm{Bu}$ filtreleme aşaması nabız bulma algoritmalarının doğru çalışabilmesi için yapılan ilk adımdır. Özellikle P ve T dalgaları üzerine eklenen gürültüler, nabız sayımında hata yapılmasına sebep olmaktadır. Filtrelenmiş EKG sinyalinde görüldüğü gibi R dalgasının tepe noktası belirlenebilecek birçok eşik değer noktasından çok daha belirgin bir büyüklüğe sahip olmaktadır.

(a)

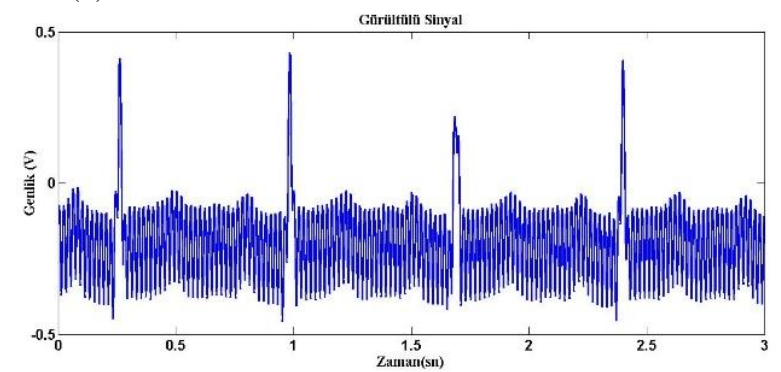

(b)

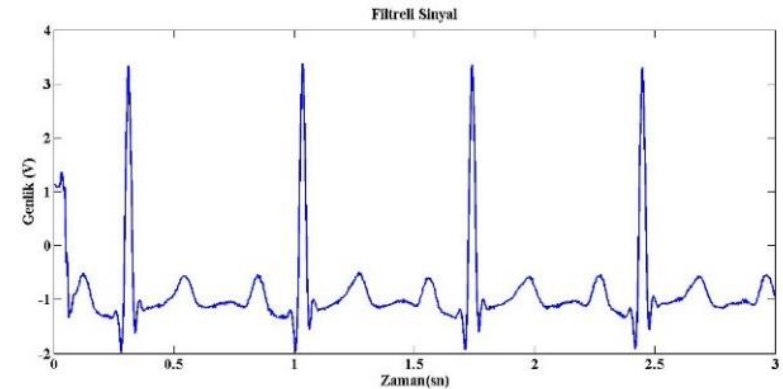

Şekil 13(a) Deneklerden Alınan Gürültülü Sinyal ve (b) Matlab Çentik ve Bant Geçiren Filtresi Çıktısı.

\subsubsection{Teager Enerji Operatörü}

Şekil 14 (a) 'da bulunan sinyal, Çentik ve Bant geçiren, filtreleri uygulanmış EKG sinyalidir. Şekil 14 (b) 'deki sinyale Teager enerji operatörü uygulanmıştır. Sonucunda $\mathrm{R}$ tepeleri güçlendirilirken diğer tepeler zayıflamıştır. $\mathrm{Bu}$ sayede kişiden kişiye değişebilen EKG voltaj değerleri, adaptif olmayan eşik değerler verilmiş olsa da hata oranı minimize edilmiş olacaktır. (a)

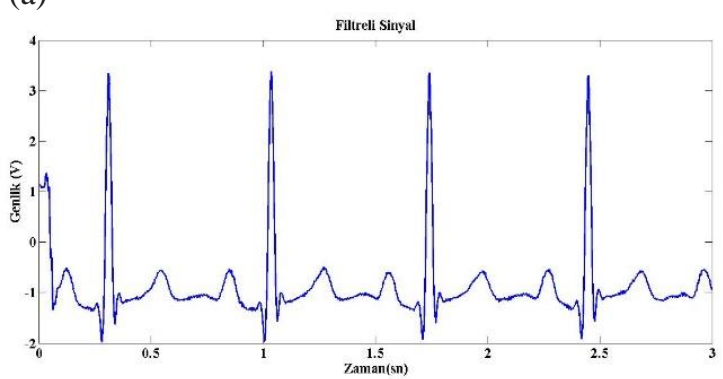

(b)

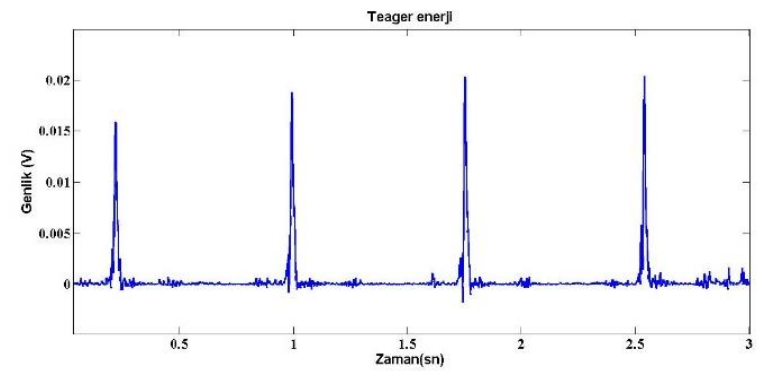

Şekil 14(a) Dijital Filtre uygulanan EKG sinyali (b) Teager Enerji operatörü uygulanan EKG sinyali

\subsubsection{R-R Aralık Hesabı}

Şekil 15 (a) 'daki sinyal, filtre uygulanmış EKG sinyalidir. Şekil 15 (b) 'de R-R aralık yöntemi uygulanmıştır. Böylece sadece $\mathrm{R}$ tepesi tespit edilip diğer tepeler tamamen bastırılmıştır [18].

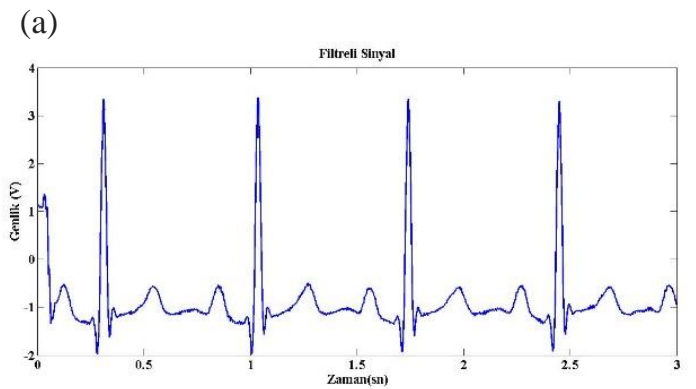

(b)

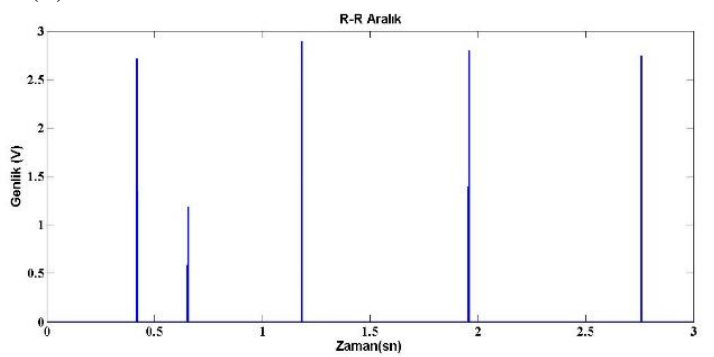

Şekil 15(a) Dijital Filtre uygulanan EKG sinyali, (b) R-R aralık uygulanan EKG sinyali

\subsubsection{Sinyal Enerjisi}

Sinyal enerjisi algoritması, sinyalin karesini aldıran bir algoritma olduğu için $\mathrm{R}$ dalgaları 1'den büyük değere sahip olduğundan kuvvetlenirken, P,Q,S,T dalgaları 0 ile 1 değerleri arasında seyreldiğinden 
genlikleri azalır. Şekil 16 (b)'de ki grafik Sinyal enerjisi algoritması uygulanan EKG verisidir.

(a)

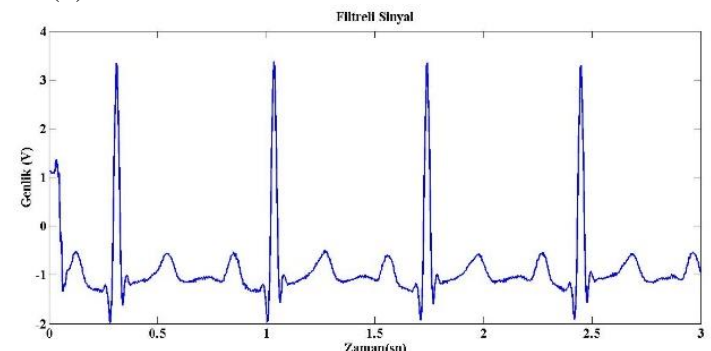

(b)

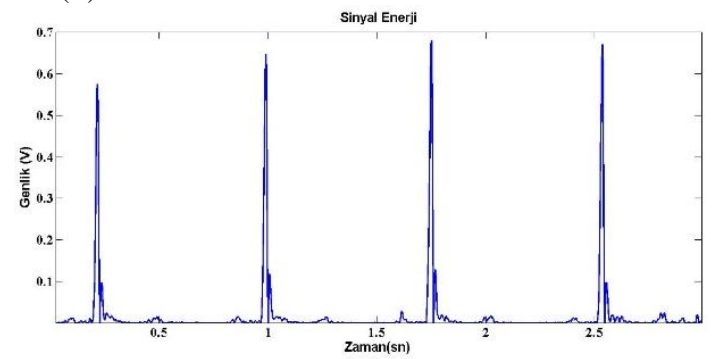

Şekil 16(a) Dijital Filtre uygulanan EKG sinyali, (b) Sinyal Enerjisi algoritması uygulanan EKG sinyali

\subsection{Gömülü Sistem İşlemci Kartlarının Karşılaştırılması}

Gömülü bir sistem belirli bir işlev veya daha büyük sistemdeki belirli işlevler için tasarlanan programlanabilir ya da kapasite olarak ayarlanabilen bilgisayar yazılım ve donanımının bileşimidir.

\subsubsection{Beaglebone}

Beaglebone, $1 \mathrm{GHz}$ işlem gücüne sahip, AM3358 işlemcili bir gömülü sistem kartıdır. 512MB DDR ram belleği kullanmaktadır. 4GB eMMC belleğinin içinde Debian GNU/Linux yüklü bir biçimde gelmektedir. 2 adet USB portu bulunmaktadır. Güç seçenekleriyse USB veya $5 \mathrm{~V}$ DC giriş ile yapılabilmektedir [22].

\subsubsection{Raspberry $\mathbf{P i}$}

Raspberry pi , 4 çekirdekli ARM mimarisine sahip işlemcisi bulunmakla beraber $1.2 \mathrm{GHz}$ işlem gücüne sahiptir. Booting ve veri depolaması için SD kart kullanılır. Üzerinde USB 2.0 portları, HDMI video çıkışı, ses çıkışı, MIPI kamera girişi, GPIO arayüzü ve $5 \mathrm{~V}$ MicroUSB güç girişi bulunmaktadır. Python programlama dili ile programlanabildiği gibi $\mathrm{BBC}$ Basic, $C$ ve Perl programlama dilleri de kullanılabilmektedir [21].

\subsubsection{Odroid}

Odroid-XU4, 8 çekirdekli Samsung Exynos5422 Cortex $^{\text {TM}}-\mathrm{A} 152 \mathrm{Ghz}$ ve Cortex ${ }^{\mathrm{TM}}-\mathrm{A} 7$ işlemcisine sahiptir. Depolama SD kart kullanılarak gerçekleştirilir. Gömülü sistem kartı 2Gb DDR3 RAM belleği bulundurmaktadır. OpenGL ve OpenCV gibi kütüphanelerin çalışmasında yüksek performans göstermektedir. Üzerinde USB 3.0 portları, HDMI video çıkışı, ses çıkışı, MIPI kamera girişi, GPIO arayüzü ve $5 \mathrm{~V}$ MicroUSB güç girişi bulunmaktadır [23].

Tablo 1 Gömülü Sistem Kartlarının Karşılaştırılması

\begin{tabular}{|c|c|c|c|}
\hline ÖZELLİKLER & ODROID & RASPBERRY PI 3 & $\begin{array}{l}\text { BEAGLEBONE } \\
\text { BLACK }\end{array}$ \\
\hline
\end{tabular}

Görsel
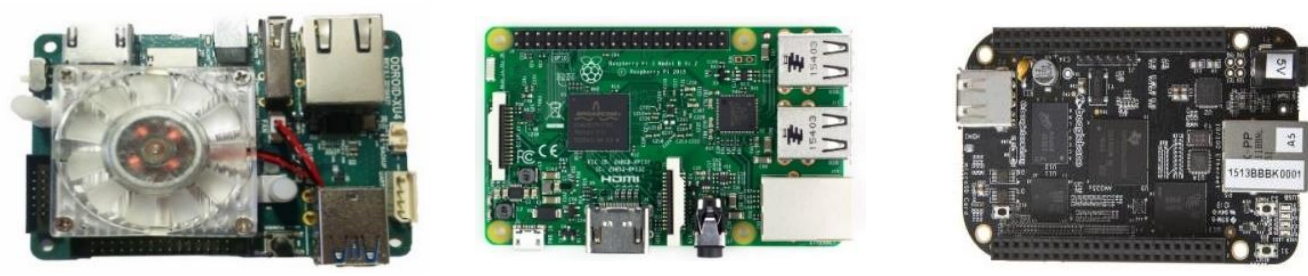

\begin{tabular}{|c|c|c|c|c|}
\hline İşlemci & 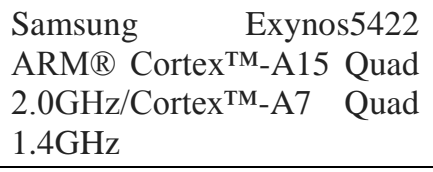 & $\begin{array}{l}\text { Quad Core 1.2GHz Broadcom } \\
\text { BCM2837 64bit CPU }\end{array}$ & $\begin{array}{ll}\text { AM335x } & 1 \mathrm{GHz} \\
\text { Cortex-A } 8 & \end{array}$ & ARM ${ }^{\circledR}$ \\
\hline Hafiza & $\begin{array}{l}\text { 2Gbyte LPDDR3 RAM PoP } \\
\text { (750Mhz, 12GB/s memory } \\
\text { bandwidth, } 2 \times 32 \text { bit bus) }\end{array}$ & 1GB RAM & $512 \mathrm{MiB}$ DDR3 & \\
\hline
\end{tabular}




\begin{tabular}{|c|c|c|c|}
\hline $\begin{array}{l}\text { GRAFİK } \\
\text { İŞLEMCİSI }\end{array}$ & $\begin{array}{l}\text { MaliTM_T628 MP6 OpenGL } \\
\text { ES } 3.1 / 3.0 / 2.0 / 1.1 \text { and } \\
\text { OpenCL 1.2 Full profile }\end{array}$ & $\begin{array}{l}\text { Broadcom VideoCore IV @ } \\
250 \mathrm{MHz}\end{array}$ & $\begin{array}{l}\text { PowerVR } \\
\text { SGX530(200 MHz) }\end{array}$ \\
\hline Ses & $\begin{array}{l}\text { HDMI Dijital ses çıkışı. } \\
\text { Opsiyonel USB ses kartı }\end{array}$ & $\begin{array}{l}3.5 \mathrm{~mm} \text { telefon jakiyla analog; } \\
\text { HDMI ile dijital ve } \mathrm{I}^{2} \mathrm{~S} \\
\text { (revizyon } 2 \text { itibarıyla) }\end{array}$ & Micro-HDMI, cape add-ons \\
\hline USB3.0 Host & $\begin{array}{l}\text { SuperSpeed USB standard A } \\
\text { type connector x } 2 \text { port }\end{array}$ & - & - \\
\hline USB2.0 Host & $\begin{array}{l}\text { HighSpeed USB standard A } \\
\text { type connector x } 1 \text { port }\end{array}$ & 4 USB 2 ports & $\begin{array}{l}1 \mathrm{x} \text { Standard A host } \\
\text { port(direct).1 x mini B device } \\
\text { port(direct) }\end{array}$ \\
\hline Görüntü Çıkışı & $\begin{array}{l}\text { HDMI } 1.4 a \text { with a Type-A } \\
\text { connector }\end{array}$ & 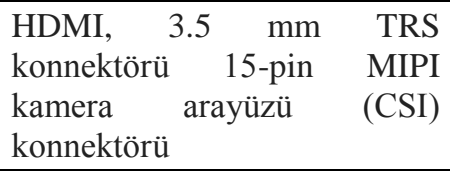 & Micro-HDMI, cape add-ons \\
\hline Depolama & $\begin{array}{l}\text { eMMC modul } \\
\text { soketi,MicroSDHC slotu }\end{array}$ & MicroSDHC slotu & $\begin{array}{l}\text { 8-bit eMMC ,MicroSDHC } \\
\text { slotu }\end{array}$ \\
\hline Ethernet LAN & 10/100/1000Mbps Ethernet & 10/100 Mbit/s Ethernet, & 10/100 Mbit/s Ethernet, \\
\hline WiFi & $\begin{array}{l}\text { USB IEEE } 802.11 \mathrm{ac} / \mathrm{b} / \mathrm{g} / \mathrm{n} \\
\text { 1T1R WLAN with Antenna } \\
\text { (External USB adapter) }\end{array}$ & 802.11n WiFi, Bluetooth 4.1 & - \\
\hline Güç Girişi & $\begin{array}{lr}4.8 \mathrm{Volt} \sim 5.2 \mathrm{Volt} & (5 \mathrm{~V} / 4 \mathrm{~A} \\
\text { Power supply } & \text { is } \\
\text { recommended) } & \end{array}$ & $\begin{array}{l}\text { 5V MicroUSB ya da GPIO } \\
\text { başlığ } 800 \mathrm{~mA}(4.0 \mathrm{~W})\end{array}$ & $\begin{array}{l}\text { Mini USB or } 2.1 \mathrm{~mm} \mathrm{x} \\
5.5 \mathrm{~mm} \mathrm{5} \mathrm{V} \mathrm{jack} \mathrm{210-460} \\
\mathrm{mA} @ 5 \mathrm{~V}\end{array}$ \\
\hline Sistem Yazılımı & $\begin{array}{l}\text { Ubuntu } 16.04+\text { OpenGL ES } \\
\text { + OpenCL on Linux Kernel } \\
\text { 4.9 LTS Android } 4.4 .2 \text { on } \\
\text { Kernel LTS } 3.10\end{array}$ & $\begin{array}{l}\text { Windows } 10 \text { IoT Core[4] ve } \\
\text { Linux }\end{array}$ & $\begin{array}{l}\text { Windows } 10 \text { IoT Core[4] ve } \\
\text { Linux }\end{array}$ \\
\hline Boyut & $85 \times 58 \times 20 \mathrm{~mm}$ & $85.60 \mathrm{~mm} \times 56.5 \mathrm{~mm}$ & $86.36 \mathrm{~mm} \times 53.34 \mathrm{~mm}$ \\
\hline
\end{tabular}

Tablo 1'de gömülü sistem kartlarının özellikleri karşılaştııılmıştır.

\subsection{Yazılım ve Arayüz Tasarımı}

Yazılım tasarımı, yazılım yöntemlerini, işlevleri, nesneleri ve sonuç yapacak işlevselliğin kullanıcılarınızın gereksinimlerini karşılayacak şekilde kodun genel yapısını ve etkileşimini tanımlama işlemidir [19].

\subsubsection{PYTHON Dili ile Tasarlanan Arayüz}

Python, nesne yönelimli, yorumlamalı, birimsel (modüler) ve etkileşimli yüksek seviyeli bir programlama dilidir. Girintilere dayalı basit sözdizimi, dilin öğrenilmesini ve akılda kalmasını kolaylaştırır. Bu da ona söz diziminin ayrıntıları ile vakit yitirmeden programlama yapılmaya başlanabilen bir dil olma özelliği kazandırır. Modüler yapıda olması sebebiyle işletim sisteminden bağımsız kod geliştirme yapılabilir. Derlemeye ihtiyaç duymadan doğrudan çalıştırılabilmesi ve basitliği ile hızlı prototipleme işlemleri için uygundur. Kullanılan donanım üzerinde hızlı sonuçlar elde edip sistemin çalışmasını analiz edebilmek için Arayüz yazılımı öncelikle Python dili ile matplotlib kütüphanesi kullanılarak şekil 17'deki ilk arayüz tasarımı oluşturulmuştur. Python yazılım diline uygun birçok kütüphane desteği bulunmaktadır. Matplotlib kütüphanesi, diğer kütüphanelerle karşılaştırılmış ve en iyi sonucu vermiştir. Ancak Python ile oluşturulan arayüzlerin gerçek zamanlı çalışmaya elverişli hızlara çıkamamasından dolayı diğer orta seviyeli programlama dillerine yönelinmiştir[20].

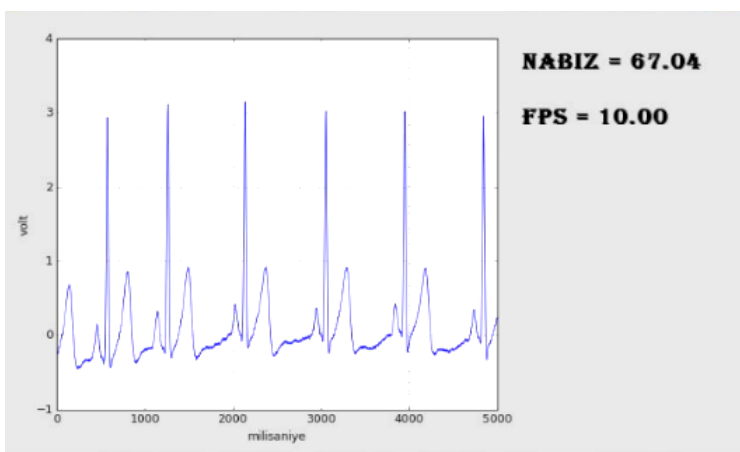

Şekil 17 Python Dili ile Oluşturulan Arayüz ile EKG işaretinin elde edilmesi. 


\subsubsection{QT ve C++ ile Oluşturulan Arayüz}

Qt, birden çok platformu destekleyen bir grafiksel kullanıcı arayüzü geliştirme araç takımıdır, programlama dili değildir. Ancak kendine has yazım biçimi ve güçlü kütüphaneleri özellikle $\mathrm{C}++$ ile Arayüz geliştirmeyi oldukça kolaylaştırmıştır. Qt, $\mathrm{C}++$ kullansa da, farklı dillere olan bağlantıları sayesinde Python, Ruby, PHP, Perl, Pascal, C\# ve Java ile de kullanılabilir. Projede kullanılan arayüzün son hali de $\mathrm{C}++$ dili ve QT kütüphaneleri kullanılarak oluşturulmuş, gömülü sistem kartları için şekil 18 'de görüldüğü gibi optimize edilmiştir [20].

Sonrasında nabız bulma algoritmaları kullanılarak, nabız ve hı performans1, gömülü sistem kartlarımıza bağlı 7' lik Raspberry Pi' a ait olan özel ekranında nabız hesaplanması ve analizleri ile birlikte monüterizasyonu sağlanmıştır.

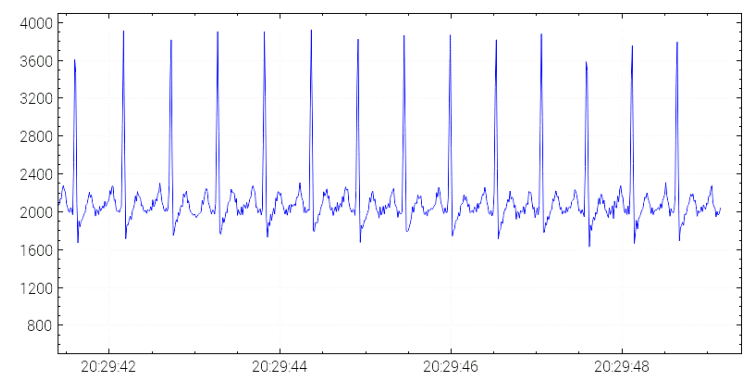

\section{FPS, HEART RATE : 114}

Şekil 18 QT C++ Arayüz Dizaynı ve EKG işaretinin elde edilmesi.

\section{Değerlendirme}

Raspberry Pi, Beaglebone ve Odroid gömülü sistem kartları arasındaki hız farkları ve performansları analiz edilerek karşılaştııılması yapılmış ve sonuçlar incelenmiştir. Tüm sonuçlar deneyler boyunca akredite bir puls oksimetre ile karşılaş̧ırılmıştır.

Saniyede alınan örnek görüntüsü sayısı 'frame per second' (FPS) olarak adlandırılır. FPS, örnek sayısı ile doğru orantılı olarak sinyalin kalitesini ve netliğini değiştirir. FPS değeri düşük olduğu zaman gerçek zamanlı sistemlerde sinyale yetişememe gibi sorunlar ortaya çıkmaktadır.

Şekil 19’ da görüldüğü gibi Beaglebone kullanılarak örnekleme hızı 35 Hz'i geçemediğinden bu aralıktaki nabız hesaplaması doğru yapılamamaktadır. Gerçek zamanlı gömülü sistemlerde, örnekleme sayısının düşük olması nedeniyle sinyale yetişilemediğinden dolayı hata oranı yüksek sonuçlar elde edilmektedir. Bu sebeple EKG için kullanımının uygun olmadığı saptanmıştır.

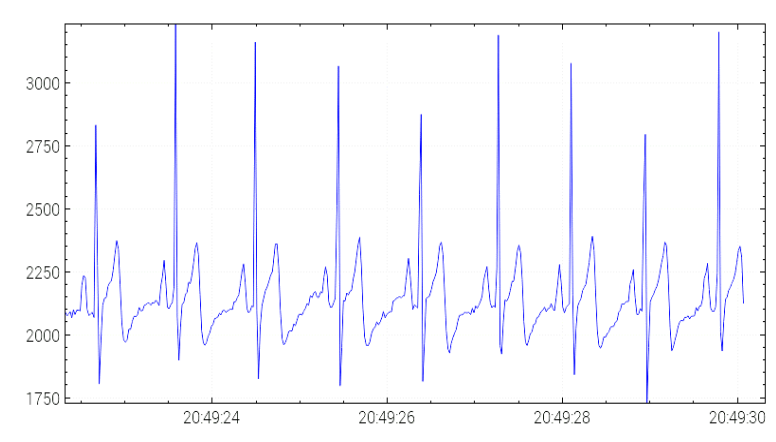

\section{FPS, HEART RATE : 70}

Şekil 19 Beaglebone Ekran Çıktısı.

Şekil 20'de olduğu gibi Raspberry $\mathrm{Pi}^{\prime}$ in örnekleme hızı $80 \mathrm{~Hz}$ civarındadır. $\mathrm{Bu}$ aralık sadece nabız hesabı için kullanılabileceği saptanmıştır. Kalibre edilmiş medikal cihazların sonuçlarıyla karşılaştırıldığında, yüksek doğruluk oranı sağlanmıştır. Maliyet ve programlama aşamalarında sağladığı kütüphane desteği sunduğu için bu sistem avantajlıdır. Yüksek örnekleme hızı gerektiren uygulamalar için kullanıma uygun değildir.

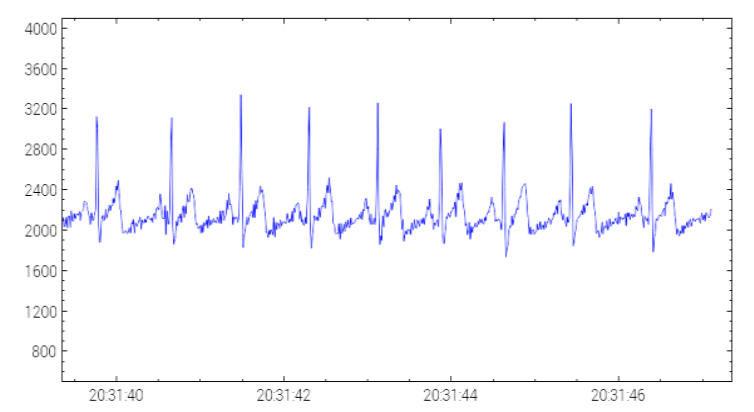

\section{FPS, HEART RATE : 69}

Şekil 20 Raspberry Pi Ekran Çıktısı.

Şekil 21 'de görüldüğü gibi Odroid örnekleme hızı $250 \mathrm{~Hz}$ civarındadır. Bu aralık nabız hesabı ve analiz algoritmalarını destekler. Yapay zeka vb. İşlem gücü gerektiren uygulamaları gerçek zamanlı olarak gerçekleyecek potansiyele sahiptir. Dahili olarak fan soğutma sistemine sahip olduğundan dolayı 1sınma problemi yoktur.

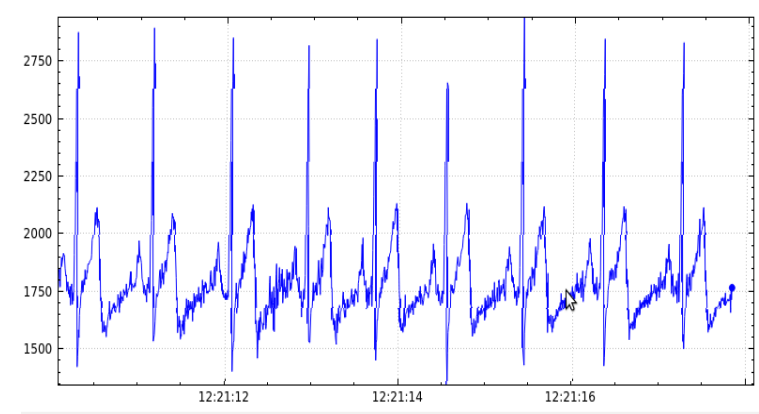

190 FPS HEART RATE : 66

Şekil 21 Odroid Ekran Çıktısı. 
Üç gömülü sistem kartını karşılaştırdığımız zaman hız ve performans bakımından en iyi sonuçları veren işlemci kartı Odroid olarak belirlenmiştir. Sadece nabız sayısını ölçmek de hayati bir önem taşıdığından fiyatının da daha uygun olması sebebiyle Raspberry Pi 'de tercih konusu olabilir.

\section{Teşekkürler}

Bu çalışma Sakarya Üniversitesi Bilimsel Araştırma Kurulu Bapk no:2015-09-04-001 ve no: 2016-09-00015 tarafindan desteklenmiştir. Çalışma boyunca katkı sağlayan Biyomedikal Mühendisliği Araştırma Laboratuvarı çalışanlarına teşekkürlerimizi sunarız.

\section{Referanslar}

[1]. Mandıracığlu A, “ Demographic chcracteristics of the elderly population in Turkey and the world, Ege Tip Dergisi, 49 (3) Ek: 39-45, 2010.

[2]. J. McKay and G. A. Mensah, The atlas of heart disease and stroke. Geneva: World Health Organization, 2005.

[3]. Webster, J. (1984). Reducing Motion Artifacts and Interference in Biopotential Recording. IEEE Transactions on Biomedical Engineering, BME-31(12), pp.823-826.

[4]. Levy, R., Labhasetwar, V., Strickberger, S., Underwood, T. and Davis, J. (1996). Controlled release implant dosage forms for cardiac arrhythmias: Review and perspectives. Drug Delivery, 3(3), pp.137-142.

[5]. Yazgan, E. (1996). Tip elektroniği. İstanbul: İTÜ.

[6]. J. G. Webster and J. W. Clark, Medical Instrumentation: Applications and design. New York: John Wiley \& Sons, 1998.

[7]. Khobragade, K. and Deshmukh, R. (1999). ECG analysis using wavelet transforms. Computer Standards \& Interfaces, 20(6-7), p.466.

[8]. Fratini, A., Sansone, M., Bifulco, P. and Cesarelli, M. (2015). Individual identification via electrocardiogram analysis. BioMedical Engineering OnLine, 14(1).

[9]. HAYIT, Tolga; ERGÜN, 'Sağlık Sektöründe Geliştirilen Mobil Uygulamaların İncelenmesi Ve Mobil Cihazlar İçin Hasta Takip Uygulaması' AJIT-e: Online Academic Journal of Information Technology . Spring2016, Vol. 7 Issue 23, p97-114. 18p.

[10]. L. Lavagno, "Embedded Systems," Embedded Systems Handbook Industrial Information Technology, 2005.

[11]. Türker, G.F., Güler, İ., "Farksal Yalıtılmış EKG Tasarımı ve Uygulaması", Süleyman Demirel Üniversitesi Fen Bilimleri Enstitüsü Dergisi, 16-3, 264-268 (2012).
[12]. Ti.com. (2017). INA128 Precision, 130-dB CMRR, 700- $\mu \mathrm{A}$, Low-Power, Instrumentation Amplifier | TI.com. [online] Available at: http://www.ti.com/product/INA128 [Accessed 16 Aug. 2017].

[13]. Furno, G. and Tompkins, W. (1983). A Learning Filter for Removing Noise Interference. IEEE Transactions on Biomedical Engineering, BME-30(4), pp.234-235.

[14]. Levkov, C., Michov, G., Ivanov, R. and Daskalov, I. (1984). Subtraction of $50 \mathrm{~Hz}$ interference from the electrocardiogram. Medical \& Biological Engineering \& Computing, 22(4), pp.371-373.

[15]. Schaumann, R., Xiao, H., Van Valkenburg, M., Van Valkenburg, M. and Van Valkenburg, M. (2011). Analog filter design. New York: Oxford University Press.

[16]. Ahlstrom, M. and Tompkins, W. (1985). Digital Filters for Real-Time ECG Signal Processing Using Microprocessors. IEEE Transactions on Biomedical Engineering, BME-32(9), pp.708-713.

[17]. Lynn, P. (1971). Recursive digital filters for biological signals. Medical \& Biological Engineering, 9(1), pp.37-43.

[18]. Lian, J., Wang, L. and Muessig, D. (2011). A Simple Method to Detect Atrial Fibrillation Using RR Intervals. The American Journal of Cardiology, 107(10), pp.1494-1497.

[19]. M. Fowler and C. Kobryn, UML distilled: a brief guide to the standard object modeling language ; Boston, MA: Addison-Wesley, 2009.

[20]. Deanfield, J. (1987). Holter monitoring in assessment of angina pectoris. The American Journal of Cardiology, 59(7), pp.C18-C22. Raspberry Pi. (2017).

[21]. Raspberry Pi - Teach, Learn, and Make with Raspberry Pi. [online] Available at: https://www.raspberrypi.org/ [Accessed 16 Aug. 2017].

[22]. Beagleboard.org. (2017). BeagleBoard.org - bone. [online] Available at: http://beagleboard.org/bone [Accessed 16 Aug. 2017].

[23]. Hardkernel.com. (2017). ODROID | Hardkernel. [online] Available at: http://www.hardkernel.com/main/main.php [Accessed 16 Aug. 2017].

[24]. T.Kantar, Ö.Köseoğlu 'Analysis of Diseases from ECG Signal' Biyomut 2014, pp 257 260. 